\title{
A Study on Reliability Differentiated Pricing of Long-Term Transactions
}

\begin{abstract}
Balho H. Kim ${ }^{\dagger}$
Abstract - Reliability differentiated pricing (RDP) is known to improve the efficiency and benefits of consumers and producers. Outage costs representing the economic and non-economic consequences of service curtailments to customers can be used as an effective parameter of RDP in electricity markets. This paper examines the theoretical aspects of an RDP scheme, and derives the optimal decisions of consumers and electric utilities for long-term transactions. The proposed RDP is demonstrated through a case study on a wheeling service.
\end{abstract}

Keywords: Reliability Differentiated Pricing (RDP), Outage Costs, Optimal Pricing

\section{Introduction}

Electricity consumers are often given the choice of different levels of service reliability [1]-[3]. Typically, customers would opt for the level of reliability that best suits their needs and processes. Such a choice is argued to "unbundle" the service, resulting in improved efficiency and benefits to both consumers and producers. However, thus far, these available priority pricing schemes have led to economic inefficiencies; they even fall short in attaining welfare maximization of the utility [4].

Real-time pricing or spot market pricing schemes have failed to consider long-run costs entailed in electricity production, such as capital costs of the added capacity. Moreover, real systems, in general, may not recover the sufficient revenue for the utility. Thus far, the suggested schemes to recover the required revenue, such as in the Ramsey-type pricing schemes applied to real-time pricing, result in welfare loss.

The pricing policy proposed in [5]-[8] could overcome most of the shortcomings entailed in both priority pricing and real-time pricing. In addition, under certain assumptions, the proposed pricing policy could recover revenues without any welfare loss. It could also differentiate the prices for varying levels of service reliability based on consumer outage costs.

In the analysis that follows, outages are assumed to occur without prior notification and that they occur in "short" duration. Outage costs are defined as costs incurred by customers due to sudden shortage in power supply; this is over and above the loss in relation to consumer benefits due to the said shortage. One reason for this is the sudden shortage of supply. Losses occur due to interruption of production processes, which could have been avoided if rescheduling is carried out. Rescheduling could only be accomplished if prior notice of the outage is conducted.

$\dagger$ Corresponding Author: Department of Electrical and Electronic Engeering, Hongik University, Korea. (bhkim@wow.hongik.ac.kr) Received: February 5, 2010; Accepted: April 5, 2010

\section{Theory of Reliability Differentiated Pricing (RDP) [4]-[7]}

A single welfare-maximizing public utility is assumed to own and operate the generating plants and the transmission network of a given electric power system, which is sold independently to customers. It is also assumed that the utility could set and communicate the prices, as well as set a different price range for each customer class, at each moment instantaneously. Supply outages occur randomly in relation to the probability of a possibly known outage. In effect, customers only learn of an outage after it occurs. Outages are assumed to be of short duration, such that customers who continue to access the utility service will not find it feasible or profitable to reschedule their production processes (i.e., change their electricity usage pattern) from the high production prices during outage duration. It is assumed that the utility could ration the supply shortages among its targeted customer classes.

\subsection{Consumer Behavior [5]}

Individual customers act independently. Customers are modeled as price-taking, profit-maximizing firms. Assume that all customers, can be classified into a finite number of classes, $i \in I$ at $\mathrm{I}=\{1, \ldots, \mathrm{N}\}$, then each class consisting of customers would have the same outage cost at a particular location. Total time $\mathrm{T}$ consists of short discrete time intervals $t \in T$. Customer i's electricity demand at time $\mathrm{t}$ is denoted by $Q_{i t}$.

Consider a short-term rational customer whose benefit from electricity usage at any time depends on consumption at that time only. Hence, the customer maximizes consumer surplus at each $t$ independently. At any time $t$, let $F_{i}$ be the value-added or benefit function for customer i's use of electricity $Q_{i}$. Then, in real-time, when there is no supply shortage, the customer would choose $Q_{i}$ to maximize 
profit $\pi$.

$$
\begin{gathered}
\text { Max } \pi=F_{i}\left(Q_{i}\right)-P_{i} Q_{i} \\
=>\frac{d F_{i}}{d Q_{i}}=P_{i}
\end{gathered}
$$

where $P_{i}$ is the price of electricity.

Fig. 1 shows the expected short-run customer demand curve DD, a very short-run customer demand curve D'E, and supply curve SS of electricity. $Q_{i}^{e}$ is the equilibrium demand of customer $i$ at time $t$ for the published expected price $P_{i}^{e}$. When supply is cut back to $Q_{i}^{0}$, the area D'FE would represent the outage cost for the customer. The area under the short-run demand curve DD gives the loss in customer benefit. $P_{i}^{0}$ is the price that the customer is willing to pay in the very short-run period for the continued supply of electricity. The very short-run demand curve is initially very steep (vertical), as it represents the price the customer (end use) is willing to pay to avoid any service interruption.

Consider the scenario wherein a shortage of supply occurs. In real-time, the customer would choose $Q_{i}$ to maximize profits:

$$
\begin{gathered}
\operatorname{Max} \pi=F_{i}\left(Q_{i}\right)-\int_{Q_{i}}^{Q_{i}^{e}} \operatorname{MOC}_{i}\left(Q_{i}\right)-P_{i} Q_{i} \\
=>\frac{d F_{i}}{d Q_{i}}+\operatorname{MOC}_{i}=P_{i}
\end{gathered}
$$

where $M O C_{i}$ is the marginal outage cost of customer $i$ as a function of usage $Q_{i}$. At $Q_{i}=Q_{i}^{0}, M O C_{i}$ is equal to D'F (Fig. 1). The benefit that the customer obtains for electricity usage $Q_{i}^{0}$ is highlighted in case of supply shortage; this is not the area under the very short-run demand

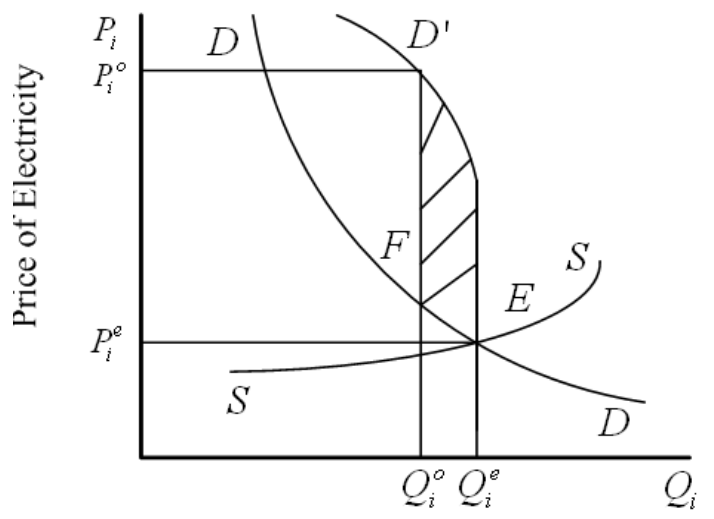

Electricity Demand curve integrated from 0 to $Q_{i}^{0}$. In contrast, the customer acts along with the very short-run demand curve to minimize losses caused by the shortage. If the duration of the outage is sufficiently long, or if the outage and subsequent rise in price are known to the customer in advance, then the customer would adjust in electricity consumption and set $\frac{d F_{i}}{d Q_{i}}=P_{i}^{0}$ (i.e., to remain on demand curve DD). However, the customer could not plan and/or adjust to the outage condition during unexpected outages of short duration; thus, the surplus of the consumer for customer $i$ is expressed by Equation (3).

Consider the case of a long-term rational customer $i$ benefitting at time $t . F_{i t}$ depends not only on the electricity usage of customer $i$ at a certain time, but also on the usage of customer $i$ at other times, and possibly, on the usage by other customers (end uses); that is,

$$
F_{i t}=F_{i t}(Q)
$$

where $Q=\left\{Q_{i t} \mid i \in I, t \in T\right\}$. Assuming that the customer seeks to maximize the total expected surplus of consumers (i.e., $E\left\{\sum_{t} F_{i t}(Q)-\operatorname{Cos} t s\right\}$ ) for time $\mathrm{T}$, where $\mathrm{E}$ is the expectation operator. Thus, the customer would choose $Q_{i t}$ to maximize the expected profit,

$$
\begin{aligned}
\operatorname{Max} \pi= & E\left[\sum_{t}\left\{F_{i t}(Q)-O C_{i t}(Q)-P_{i t} Q\right\}\right] \\
& =>\frac{\partial \sum_{\tau \in T} F_{i t}}{\partial Q_{i t}}-\frac{\partial \sum_{\tau \in T} O C_{i t}}{\partial Q_{i t}}=P_{i t}
\end{aligned}
$$

where $P_{i t}$ is the expected price of electricity. The outage cost function includes loss in customer benefit (the bold letters represent expected values). Thus, the customer would equate the expected net marginal benefit to the expected price of electricity.

In the analysis that follows, the value-added function of the customer is extended to include both real and reactive power demands at the fundamental frequency of $60 \mathrm{~Hz}$ :

$$
F_{i t}=F_{i t}\left(P_{i}^{d}\left(p_{i}\right), Q_{i}^{d}\left(q_{i}\right)\right)
$$

where

$$
\begin{aligned}
& P_{i}^{d}: \text { vector of real power demands of customer } i, \\
& Q_{i}^{d}: \text { vector of reactive power demands of customer } i, \\
& p_{i}: \text { vector of prices of real power for customer } i, \text { and } \\
& q_{i}: \text { vector of prices of reactive power for customer } i .
\end{aligned}
$$

Fig. 1. Customer Demand and the Supply Curves of Electricity. 


\subsection{Objective}

The objective of the short-run operating and optimal pricing problem in a welfare-maximizing utility using the criterion of consumers plus producers surplus can be stated as

$$
\begin{aligned}
\operatorname{Max} W & =E\left[\sum _ { t } \left\{\sum_{i} F_{i t}\left(P_{i}^{d}, Q_{i}^{d}\right)-\sum_{i} O C_{i t}\left(P_{i}^{u}, Q_{i}^{u}\right)\right.\right. \\
& \left.\left.-\sum_{i} P C_{i t}\left(P_{i t}^{g}, Q_{i t}^{g}\right)-\sum_{i} E C_{i t}\left(P_{i t}^{s}, Q_{i t}^{s}\right)\right\}\right]
\end{aligned}
$$

where

$E[\bullet]$ : expected value of the argument, $F_{i t}\left(P_{i}^{d}, Q_{i}^{d}\right)$ : short-run value-added function of customer $i$, $P_{i}^{d}$ : real power demand of customer $i$,

$Q_{i}{ }_{i}^{d}$ : reactive power demand of customer $i$,

$P_{i}^{u}$ : outage of real power for customer $i$,

$Q_{i}^{u}$ : outage of reactive power for customer $i$,

$P_{i}^{g}$ : generation of real power by generator $i$,

$Q_{i}^{g}$ : generation of reactive power by generator $i$,

$P_{i}^{s}$ : emergency purchase of real power at bus $i$,

$Q_{i}^{s}$ : emergency purchase of reactive power at bus $i$,

$O C_{i t}\left(P_{i}^{u}, Q_{i}^{u}\right)$ : outage cost function of customer $i$,

$P C_{i t}\left(P_{i t}^{g}, Q_{i t}^{g}\right)$ : cost of producing real and reactive power at bus $i$, and

$E C_{i t}\left(P_{i t}^{s}, Q_{i t}^{s}\right)$ : cost of purchasing real and reactive power at bus $i$.

All decision variables, with the exception of those involving reactive power, are nonnegative. . The objective function is assumed as a differentiable with a continuous first derivative. For optimal operating and pricing strategies, the objective is to maximize the subject for the operating and network constraints inherent in the system.

\section{Optimal Long-Term Prices}

Section 2 deals with the short-run problem of a welfaremaximizing utility from which optimal short-term reliability-differentiated prices are derived from. This section examines the long-run social welfare maximization problem of the utility developed from the previous section. Based on these, we derive the differentiated prices of long-term reliability, which considers cost of capital or other fixed costs of production. Long-term transactions, such as firm capacity purchased from or by the utility, or purchased from individual generators in the case of a network utility, the access to transmission services and wheeling transactions would require the provision of long-term prices in order for the participants to enter into contracts and to accommodate optimal investment decisions.

Consider the long-run resource planning problem of a welfare-maximizing utility. To obtain the given values of customer demands, the welfare-maximizing utility must first solve the following problem of minimizing long-run expected societal costs in order to determine the optimal resource plan,

$$
\begin{aligned}
\operatorname{Max} W= & E\left[\sum _ { t } \left\{\sum_{i} F_{i t}\left(P_{i}^{d}, Q_{i}^{d}\right)-\sum_{i} O C_{i t}\left(P_{i}^{u}, Q_{i}^{u}\right)-\sum_{i} P C_{i t}\left(P_{i t}^{g}, Q_{i t}^{g}\right)\right.\right. \\
& \left.\left.-\sum_{i} E C_{i t}\left(P_{i t}^{s}, Q_{i t}^{s}\right)\right\}\right]-\sum_{i} C C_{i}\left(K_{i}^{p}, K_{i}^{q}\right) \\
& -\sum_{i} S C_{i}\left(S_{i}^{p}, S_{i}^{q}\right)-\sum_{k} T C_{k}\left(T_{K}^{\max }\right)
\end{aligned}
$$

which is subject to the following constraints:

$$
\begin{aligned}
& P_{i t}^{g}+P_{i t}^{s}+P_{i t}^{u}-P_{i t}^{d}-\sum_{j}\left|V_{i t}\right|\left|V_{j t}\right|\left|V_{i j}\right| \operatorname{Cos}\left(\theta_{i j}+\delta_{j t}-\delta_{i t}\right)=0 \\
& Q_{i t}^{g}+Q_{i t}^{s}+Q_{i t}^{u}-Q_{i t}^{d}+\sum_{j}\left|V_{i t}\right|\left|V_{j t}\right|\left|V_{i j}\right| \operatorname{Sin}\left(\theta_{i j}+\delta_{j t}-\delta_{i t}\right)=0 \\
& 0 \leq P_{i t}^{g} \leq K_{i}^{p} a_{i t} \\
& -K_{i}^{q} a_{i t} \leq Q_{i t}^{g} \leq K_{i}^{q} a_{i t} \\
& \left|T_{i j t}\right| \leq T_{i j}^{\max } b_{i j t} \\
& V_{i}^{\min } \leq\left|V_{i t}\right| \leq V_{i}^{\max } \\
& g_{t}\left(P_{t}^{d}, Q_{t}^{d}, P_{t}^{g}, Q_{t}^{g}, P_{t}^{s}, Q_{t}^{s}\right) \leq 0 \\
& 0 \leq P_{i t}^{s} \leq S_{i}^{p} \\
& 0 \leq Q_{i t}^{s} \leq S_{i}^{q} \\
& e_{i}^{n} P_{i t}^{g} \leq E_{i t}^{n}+A_{i t}^{n} \\
& \sum_{i} e_{i}^{n} P_{i t}^{g} \leq E_{t}^{n}+A_{t}^{n} \\
& \mathrm{I}_{\mathrm{it}}^{\mathrm{h}}=d_{\mathrm{i}}^{\mathrm{h}} P_{\mathrm{it}}^{\mathrm{d}} \quad \mathrm{h}=2,3,4, \ldots \\
& V_{\mathrm{it}}^{\mathrm{h}}=\sum_{j} Z_{\mathrm{ij}}^{\mathrm{h}} I_{\mathrm{jt}}^{\mathrm{h}} \quad \mathrm{h}=2,3,4, \ldots \\
& T H D_{t}=\sum_{i} \frac{\sum_{h=2}^{\infty}\left|V_{\mathrm{it}}^{\mathrm{h}}\right|^{2}}{N B\left|V_{\mathrm{it}}^{1}\right|^{2}} \\
& T H D_{t} \leq D_{\max } \\
& 0 \leq P_{i t}^{u} \\
& 0 \leq Q_{i t}^{u}
\end{aligned}
$$

where

$K_{i}^{p}$ : real power generation capacity of generator i,

$K_{i}^{q}$ : reactive power generation capacity of generator i, $S_{i}^{p}$ : real power spinning reserve capacity at bus $\mathrm{i}$, 
$S_{i}^{q}$ : reactive power spinning reserve capacity at bus $\mathrm{i}$, and

$T_{k}^{\max }$ : volt-ampere transmission capacity of line $\mathrm{k}$

are the decision variables. In addition,

$C C_{i}\left(K_{i}^{p}, K_{i}^{q}\right)$ : capital cost of capacity for generator i,

$S C_{i}\left(S_{i}^{p}, S_{i}^{q}\right)$ : purchase price of spinning reserve at bus i, and

$T C_{k}\left(T_{k}^{\max }\right)$ : capital cost of capacity for transmission line $\mathrm{k}$.

This problem can be solved accordingly. By taking $P_{i t}^{d}$ and $Q_{i t}^{d}$ as the parameters of the problem, in order to obtain the optimal values of all variables as the functions of the parameters (i.e., $P_{i t}^{d}$ and $Q_{i t}^{d}$ (sensitivity theorem), the objective function can be written as

$$
\begin{aligned}
W_{\text {opt }}= & \sum_{t}\left\{\sum_{i} F_{i t}\left(P_{i}^{d}, Q_{i}^{d}\right)-\sum_{i} O C_{i t}\left(P_{t}^{d}, Q_{t}^{d}\right)-P C_{t}\left(P_{t}^{d}, Q_{t}^{d}\right)-E C_{t}\left(P_{t}^{d}, Q_{t}^{d}\right)\right\} \\
& -\sum_{i} C C_{i}\left(P^{d}, Q^{d}\right)-\sum_{i} S C_{i}\left(P^{d}, Q^{d}\right)-\sum_{k} T C_{k}\left(P^{d}, Q^{d}\right)
\end{aligned}
$$

where

$$
P^{d}=\left\{P_{i t}^{d} ; \forall i \in I, \forall t \in T\right\}, Q^{d}=\left\{Q_{i t}^{d} ; \forall i \in I, \forall t \in T\right\} .
$$

The customer sets the expected net marginal benefit from the electricity consumption equal to the expected price of electricity. Then, the respective optimal long-term prices for real and reactive power inducing customers to behave in a social welfare-maximizing manner are given by:

$$
\begin{aligned}
& P_{j t}^{L}=\sum_{i \neq j} \frac{\partial O C_{i t}}{\partial P_{j t}^{d}}+\frac{\partial P C_{t}}{\partial P_{j t}^{d}}+\frac{\partial E C_{t}}{\partial P_{j t}^{d}} \\
& q_{j t}^{L}=\sum_{i \neq j} \frac{\partial O C_{i t}}{\partial Q_{j t}^{d}}+\frac{\partial P C_{t}}{\partial Q_{j t}^{d}}+\frac{\partial E C_{t}}{\partial Q_{j t}^{d}}
\end{aligned}
$$

Thus, by employing socially optimal investment decision-making, long-term prices of real and reactive power could coincide with short-term reliability-differentiated prices. However, optimal investments require the evaluation of future uncertainty, which is often difficult to carry out. Another difficulty is the unavailability of proper demand models that could capture the interdependence of intertemporal demands. In principle, one should utilize benefit functions that depend on the entire time stream of demand rather than a single point in time.

\section{Case Study}

\subsection{Implications for Pricing Firm Capacity}

Firm capacity refers to the generation of capacity that is purchased by the utility from neighboring utilities, namely, independent power producers (IPP) and cogenerators, in order to provide customers with long-run higher levels of service reliability. The price paid for firm capacity should equal the value or marginal benefit that the customers derive from the added capacity. Purchasing firm capacity is a long-term contract forged to protect against the loss of customer load due to unplanned outage of generating units. Thus, in order to determine the optimal price of firm capacity purchases, the long-run problem of welfare-maximizing utility given in Equations (9)-(10) must be considered. Again, this problem could be solved when obtaining the optimal values of all variables as functions of the parameters of the problem, in particular, $K_{i}^{p}$ and $K_{i}^{q}$ (sensitivity theorem).

The shadow price of added capacity (i.e., the Lagrange multiplier of the capacity constraint) represents the willingness of customers to pay for the obtained added capacity. Based on Equations (12) and (13), the respective optimal firm capacity purchase prices at bus $\mathrm{j}$ for real and reactive power capacity are expressed by

$$
\begin{gathered}
\mu_{j}^{P}=-\sum_{t \in T}\left\{\sum_{i} \frac{\partial O C_{i t}}{\partial K_{j}^{P}}+\frac{\partial P C_{t}}{\partial K_{j}^{P}}+\frac{\partial E C_{t}}{\partial K_{j}^{P}}\right\} \\
\mu_{j}^{q}=-\sum_{t \in T}\left\{\sum_{i} \frac{\partial O C_{i t}}{\partial K_{j}^{q}}+\frac{\partial P C_{t}}{\partial K_{j}^{q}}+\frac{\partial E C_{t}}{\partial K_{j}^{q}}\right\}
\end{gathered}
$$

\subsection{Numerical Example: Calculation of Long-Term Rates}

Consider the simple four-bus system in Fig. 2. In the figure, Gi and Li represent generating unit and load at Bus $i$, while Ti represents transmission line $i$. The characteristics of the system are as follows:

G1: Rating $=200 \mathrm{MW}, \mathrm{FOR}=0.00$, Generation cost $=$ \$30/MWH

$\mathrm{G} 2$ : Rating $=250 \mathrm{MW}, \mathrm{FOR}=0.10$, Generation cost $=$ \$0/MWH

$\mathrm{G} 3$ : Rating $=110 \mathrm{MW}, \mathrm{FOR}=0.00$, Generation cost $=$ \$40/MWH

$\mathrm{G} 4$ : Rating $=250 \mathrm{MW}, \mathrm{FOR}=0.20$, Generation cost $=$ \$20/MWH

L1: Customer load $=180 \mathrm{MW}$, Outage cost $=\$ 600 /$ $\mathrm{MWH}$

L2: Customer load $=150 \mathrm{MW}$, Outage cost $=\$ 200 /$ MWH

L3: Customer load $=100 \mathrm{MW}$, Outage cost $=\$ 600 /$ $\mathrm{MWH}$

L4: Customer load $=200 \mathrm{MW}$, Outage cost $=\$ 400 /$ MWH

$\mathrm{T} 1:$ Rating $=100 \mathrm{MW}, \mathrm{FOR}=0.00$

T2: Rating $=120 \mathrm{MW}, \mathrm{FOR}=0.00$

T3: Rating $=80 \mathrm{MW}, \mathrm{FOR}=0.30$

T4: Rating $=80 \mathrm{MW}, \mathrm{FOR}=0.00$ 


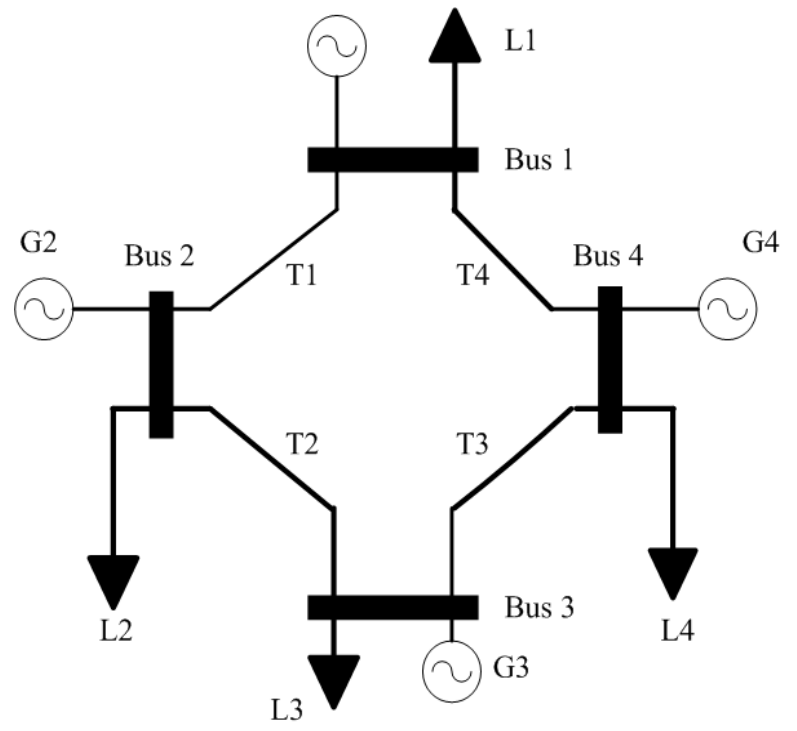

Fig. 2. Four-Bus Power System for Sample Rate Calculations.

In the model, there are two generating units (G2 and G4) and one transmission line (T3) with non-zero forced outage rates. Thus, at each instance over time, there are eight possible system configurations or states that the system can utilize. The load at each bus is assumed consisting of 1 MW of individual customer load for those that belong to the same class (i.e., classes that have the same outage cost.)

Assuming that the system is operated optimally by a single welfare-maximizing utility, then the expected reliability-differentiated price for customers of class $\mathrm{j}$ is given by

$$
P_{j}=\sum_{i \neq j} \frac{\Delta O C_{i}}{\Delta L_{j}}+\frac{\Delta P C}{\Delta L_{j}}
$$

Thus, the expected prices for the customer classes of the system are

$$
\begin{aligned}
& P_{1}=\$ 72.96 / \mathrm{MWH}, P_{2}=\$ 52.45 / \mathrm{MWH} \\
& P_{3}=\$ 72.96 / \mathrm{MWH}, P_{4}=\$ 87.72 / \mathrm{MWH}
\end{aligned}
$$

The probability of service interruption (POSI) for customers of each class, which measures the level of reliability in which each customer class is served, are

$$
\begin{aligned}
& \mathrm{POSI}_{1}=0.0000, \mathrm{POSI}_{2}=0.0825, \\
& \mathrm{POSI}_{3}=0.0000, \mathrm{POSI}_{4}=0.0746 .
\end{aligned}
$$

The total expected cost of unserved energy for this linear system is

$$
O C=\sum_{i} M O C_{i} P U_{i}=\sum_{i} \frac{\Delta O C_{i}}{\Delta L_{i}}=\$ 8,444.00
$$

where $M O C_{i}$ is the marginal outage cost of customer $i$ (e.g., $M O C_{2}=\$ 200 / \mathrm{MWH}$ ).
The total expected revenue from the sale of electric power is

$$
T R=\sum_{i} P_{i} L_{i}=\$ 45,848.80
$$

The total expected cost of generation is

$$
P C=\sum_{i} M P C_{i} P G_{i}=\$ 9,612.00
$$

where $M P C_{i}$ is the marginal production cost of generator $i$ (e.g., $M P C_{1}=\$ 30 / \mathrm{MWH}$ ).

The price of capacity purchase from generator $i$ is given by

$$
\mu_{i}=-\sum_{j} \frac{\Delta O C_{j}}{\Delta K_{i}}-\frac{\Delta P C}{\Delta K_{i}}
$$

Thus, the prices of capacity purchase from the generators of the system are

$$
\begin{aligned}
& \mu_{1}=\$ 42.96 / \mathrm{MW}, \quad \mu_{2}=\$ 48.96 / \mathrm{MW} \\
& \mu_{3}=\$ 40.16 / \mathrm{MW}, \quad \mu_{4}=\$ 21.60 / \mathrm{MW} \text {. }
\end{aligned}
$$

The total payment to the generators for capacity purchase is

$$
C P=\sum_{i} \mu_{i} K_{i}=\$ 30,649.60
$$

The price of capacity purchase from transmission line $\mathrm{k}$ is given by

$$
\eta_{k}=-\sum_{j} \frac{\Delta O C_{j}}{\Delta T_{k}^{\max }}-\frac{\Delta P C}{\Delta T_{k}^{\max }}
$$

Thus, the prices of capacity purchase from the transmission lines are

$$
\begin{aligned}
& \eta_{1}=\$ 0.00 / \mathrm{MW}, \quad \eta_{2}=\$ 0.00 / \mathrm{MW} \\
& \eta_{3}=\$ 25.20 / \mathrm{MW}, \eta_{4}=\$ 44.64 / \mathrm{MW}
\end{aligned}
$$

The total payment to the transmission lines for capacity purchase is

$$
T P=\sum_{k} \eta_{k} T_{k}^{\max }=\$ 5,587.20
$$

The sum total of all expected costs/payments for the system is

$$
\mathrm{TC}=\mathrm{PC}+\mathrm{CP}+\mathrm{TP}=\$ 45,848.80
$$


Hence, under RDP, the total expected revenue from sales to customers is exactly equal to the sum total of all expected costs/payments for the system (i.e., $\mathrm{TR}=\mathrm{TC}$ ).

\section{Conclusion and Future Study}

Outage costs play an essential role in electricity pricing and in the planning of electrical power systems. The central role of outage costs in the optimal investment planning of the power system from a societal point of view, particularly for setting economic reliability standards in the generation, transmission, and distribution planning, has been emphasized by many studies. As outage costs reflect the prices at which customers are willing to pay for continued service in a very short run, it can provide for the economically efficient basis when rationing supply at times of shortages. Unbundling the services by offering consumers options on trade offs for service reliability, quality, and price can potentially increase the economic efficiency of the entire system, producing benefits for both the utility and the customers. In this sense, outage costs can be an efficient basis of RDP.

We propose $\mathrm{RDP}$ in examining the proposed pricing scheme of long-term transaction, putting emphasis on the long-term contract of firm capacity. The proposed pricing scheme is applicable and compliant when deriving at optimal decisions. However, the implications of the proposed pricing scheme for the wheeling service and transmission service needs to be dealt with further by future studies.

\section{Acknowledgment}

This work has been supported by KEPCO (R-200702210: Development of Electric Power Market Simulator), funded by the Ministry of Knowledge and Economy (MKE)

\section{References}

[1] Chao, H. P., S. Oren, S. Smith, and R. Wilson, "Service Design in Electric Power Industry," Report P6543, Electrical Power Research Institute, 1990.
[2] Chao, H. P., and R. Wilson, "Priority Service: Pricing, Investment, and Market Organization," American Economic Review, 77: 899-916, 1987.

[3] Chao, H. P., S. Oren, S. Smith, and R. Wilson, "Selected Papers on Priority Service Methods," Report P-5350, Electrical Power Research Institute, 1987.

[4] Rau, N. S. and Y. Hegazy, "Reliability Differentiated Pricing of Electricity Service," National Regulatory Research Institute, Columbus, Ohio, 1990.

[5] Baughman, M. L. and S. N. Siddiqi, "Real-Time Pricing of Reactive Power: Theory and Case Study Results," IEEE Transactions on Power Apparatus and Systems, Vol. 6, No. 1, February 1991, pp. 23-29.

[6] Baughman, M. L., and S. N. Siddiqi, and J. Zarnikau, "Advanced Pricing in Electrical Systems," Working Paper, Center for Energy Studies, University of Texas at Austin, February 1993.

[7] Siddiqi, S. N. and M. L. Baughman, "Reliability Differentiated Real-Time Pricing of Electricity," Paper 92-WM-115-6, IEEE 1992 Winter Power Meeting, NY, January 26-30, 1992.

[8] Siddiqi, S. N. and M. L. Baughman, "Optimal Pricing of Non-utility-generated Electric Power," Paper 93WM-149-5, IEEE 1993 Winter Power Meeting, Columbus, Ohio, January 31 - February 5, 1993.

[9] Wilson, R., "Priority Service Methods," presented at the EPRI/UERG Berkeley Symposium, Berkeley, California, September 12-14, 1990.

[10] Woo, C. K. and N. Toyama, "Service Reliability and the Optimal Interruptible Rate Option in Residential Electricity Pricing,” Energy Journal, 7:3, 1986.

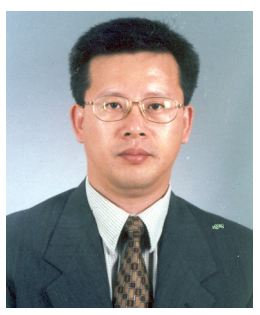

Balho H Kim was born in Bong-Hwa, Korea. He received his BSEE from Seoul National University, and his MSEE and Ph.D from the University of Texas at Austin. Currently, he is a professor in the School of Electrical Engineering at Hongik University. His research fields include Optimal Power Flow, Public Utility Pricing, Electricity Market Design \& Operation, Resource Planning, and Demand Management. 